\title{
O "imperialismo" chileno durante a Guerra do Pacífico (1879-1884)
}

Flávia Schettino Marques Gomes ${ }^{1}$

MCEVOY, Carmen. Guerreros Civilizadores: política, sociedad y cultura en Chile durante la Guerra del Pacífico. Santiago: Ediciones Universidad Diego Portales, 2011. $431 \mathrm{p}$.

Resenha recebida em: 29/06/2013

Resenha aprovada em: 30/08/2013

Carmen McEvoy nasceu no Peru, é historiadora e professora na University of the South, Sewanee, no Tennessee, EUA. É também mestre pela Pontifícia Universidad Católica del Perú e doutora pela University of California, em San Diego. Sua tese de doutoramento versou sobre o republicanismo no Peru do século XIX e inaugurou uma série de estudos da autora sobre as relações entre Peru, Chile e Bolívia, dos quais se destacam Armas de Persuasión Masiva: retórica y ritual en la Guerra del Pacífico (2010) e Guerreros Civilizadores: política, sociedad y cultura en Chile durante la Guerra del Pacífico (2011). Desse último, trata a presente resenha.

Guerreros Civilizadores é a continuação das pesquisas iniciadas em sua obra anterior, Armas de Persuasión Masiva, e aborda a Guerra do Pacífico, tema bastante conhecido e estudado por McEvoy. Ocorrida no final do século XIX, mais precisamente entre os anos de 1879 e 1884, essa guerra - que envolveu Chile, Bolívia e Peru na disputa pela posse do território rico em minerais situado ao norte do que hoje é o Chile foi um episódio importantíssimo na configuração dos espaços nacionais dos países envolvidos. A guerra foi deflagrada a partir do impasse entre os governos de Chile e Bolívia em relação ao pagamento de impostos sobre a exploração das riquezas minerais bolivianas, por empresas chilenas que lá se instalaram. O conflito tornou-se tri nacional

\footnotetext{
${ }^{1}$ Mestranda no departamento de História da Universidade Federal de Minas Gerais (UFMG), Brasil. E-mail: flavia.schettino72@gmail.com

Revista Eletrônica da ANPHLAC, ISSN 1679-1061, n.15, p. 307-312, jul./dez. 2013.
} 
devido a um pacto de ajuda mútua, em caso de guerra, firmado anos antes entre Bolívia e Peru. O desfecho foi favorável aos chilenos, que puderam anexar ao seu território às partes em disputa com seus vizinhos. A Bolívia perdeu sua saída para o Oceano Pacífico, e o Peru perdeu a rica província de Tarapacá, principal centro de exploração do cobre chileno até os dias de hoje.

Guerreros Civilizadores resulta de uma longa e exaustiva pesquisa em diversas fontes, fato esse que coloca o livro como uma referência bibliográfica importante. Dentre elas, destacam-se manuscritos e correspondências trocadas entre os protagonistas do conflito, incluindo presidentes e ministros chilenos que estavam no comando da nação durante a guerra, bem como escritos dos próprios soldados que redigiam seus diários nos campos de batalha. Foram utilizados ainda vinte e quatro jornais que circularam no Chile e no Peru durante a guerra, atas governamentais, boletins, discursos parlamentares e religiosos proferidos antes e durante o período belicoso. A autora realiza também um interessante debate historiográfico por meio da análise de vasta bibliografia. Para esse debate, ela utilizou autores, historiadores ou não, contemporâneos ao evento e posteriores a ele, que discorreram sobre o tema ao longo dos mais de cento e trinta anos de seu início.

A proposta de McEvoy em Guerreros Civilizadores é analisar a sociedade chilena, durante os anos do conflito, desde o ponto de vista social, cultural e político. A "Guerra Cívica", conceito muito utilizado pela autora, é descrita como um projeto desenvolvido pela elite governante do Chile, com o intuito de anexar os territórios ricos em minerais dos países vizinhos. Naquele contexto, vários atores sociais apareceram para cumprir o propósito determinado pelo referido grupo que, além da ideia de expansão territorial, também apostou na guerra como início de um processo civilizador dos "bárbaros selvagens", que formavam as sociedades peruana e boliviana. O tom racista evocado pelos chilenos está presente na obra e serve como justificativa para a "Guerra Cívica”. Segundo a autora, o pensamento por detrás do conflito era a suposta "civilidade" e "superioridade" dos chilenos em relação aos seus vizinhos, que deveria ser ampliada e difundida às demais populações pelo bem do continente. $\mathrm{O}$ foco principal da obra é a análise da dinâmica social que se apresenta no decorrer do período, vista como uma espécie de "imperialismo" sul-americano. O Chile aproveita a posição de grande explorador de minerais em terras estrangeiras, para levar a sua presumida Revista Eletrônica da ANPHLAC, ISSN 1679-1061, n.15, p. 307-312, jul./dez. 2013. 
civilização e desenvolvimento àqueles que "necessitavam" dela. Para a autora, a legitimidade da guerra, abordada desde o ponto de vista chileno, reside na ideia de difundir para o mundo a imagem de um país civilizado que, diferentemente de seus adversários, seria um exemplo de república a ser seguido na América do Sul. Esse argumento conduz o livro, e a análise das fontes feita por McEvoy evidencia a intenção do Chile em se projetar como o baluarte da civilidade republicana. Em suas palavras, McEvoy coloca que

\begin{abstract}
o transcendental enfrentamento no sul do Pacífico deixa de ser um simples feito militar para se converter em um arauto dos dilemas, tensões, conflitos e, por que não dizer, dos anseios de uma república jovem e pujante que viu na guerra a oportunidade para estabelecer não somente sua autonomia econômica, mas um lugar de destaque no "cenário das nações civilizadas". (p.14)
\end{abstract}

Ao utilizar os relatos pessoais dos soldados, descritos em seus diários de campanha, a autora consegue demonstrar o tom patriótico dos discursos proferidos tanto pelos meios de comunicação que circulavam no país, quanto pelos políticos que os utilizavam em seus palanques, com o intuito de motivar a população civil e militar a pegar em armas. Os jovens combatentes que se aventuraram por terras estranhas na defesa da pátria ultrajada demonstram em seus escritos a ideia expansionista e civilizadora proposta pelo Estado em guerra. As correspondências trocadas entre soldados e seus familiares também traziam o tom nacionalista que McEvoy enfatiza no decorrer de seu trabalho. Outra fonte muito bem explorada por ela são os discursos eclesiásticos, assim como os relatos dos religiosos que acompanharam os destacamentos de soldados durante as batalhas e nos acampamentos erguidos em território ocupado. $\mathrm{Na}$ medida em que o exército chileno avançava sobre os inimigos, as pregações feitas, tanto na capital da república, quanto nas igrejas provincianas, estavam repletas de comparações entre os chilenos e os cruzados europeus, revestindo a pugna de uma aura de "guerra santa". Nesse sentido, muitos são os argumentos que mostram o grau de religiosidade presente nos discursos "civilizadores" do Chile. Outro ponto importante discutido no livro é a oportunidade que a Igreja chilena teve de voltar ao cenário nacional, depois de uma longa disputa ideológica travada com um Estado liberal que ganhava força naquele momento. Segundo ela, a laicização do Estado diminuiu a influência da Igreja sobre a sociedade, e a guerra teria trazido de volta esse espaço perdido.

Revista Eletrônica da ANPHLAC, ISSN 1679-1061, n.15, p. 307-312, jul./dez. 2013. 
As cartas recebidas e enviadas pelos dois presidentes chilenos no poder durante o conflito, Aníbal Pinto e Domingo Santa Maria, também foram analisadas e constituem peças respeitáveis da construção do imaginário nacional e nacionalista que se configurou no período. As posições políticas e ideológicas dos presidentes e de seus assessores testificam o argumento da autora em relação ao interesse expansionista e civilizador que a Guerra do Pacífico alimentou entre os chilenos.

Os capítulos são dispostos em uma ordem que procura demonstrar o processo histórico pelo qual passou a sociedade chilena enquanto durou o conflito. Apresentando momentos, desde a chamada às armas até a tomada da capital peruana, Lima, a narrativa apresenta as campanhas e batalhas travadas com os exércitos inimigos, principalmente o peruano, e coloca em evidência o desenrolar dos fatos junto a seus atores. As incertezas e precariedades que acometeram os envolvidos direta ou indiretamente no conflito são expostas de maneira a permitir que o leitor tenha um entendimento claro daquela complexa realidade marcial. Com uma sofisticada trama de atores, em que se percebe o enorme esforço investigativo dedicado ao trabalho, a autora extrai do cenário de guerra seus principais elementos, ou seja, as dinâmicas política, social e cultural intrincadas em todos os níveis de sociabilidade.

O último capítulo do livro, destinado à compreensão do processo de ocupação chilena sobre o território peruano, consolida e justifica a ideia de dominação com o intuito de civilização que foi elaborada ao longo do texto. Ocupar a sede do antigo vicereinado espanhol reitera o argumento de que o Chile tinha em seu "destino" a tarefa de civilizar seus vizinhos, o que legitimou o conflito para eles. O grande desafio dessa nação civilizadora era manter seu discurso de "superioridade", em meio a um contexto de caos e destruição política, econômica e social, em que se encontrava o Peru depois da invasão de Lima pelo exército inimigo. Utilizando correspondências dos oficiais das forças armadas, as cartas entre o presidente e seus assessores e as notícias dos jornais, a autora explana sobre as contradições existentes entre o ideal "civilizador" chileno e a realidade de uma guerra violenta que ceifou uma enorme quantidade de vidas humanas.

O livro, porém, apresenta algumas ausências. A questão relativa ao Combate Naval de Iquique - um dos pontos de definição do desfecho do conflito aceito entre os historiadores da Guerra do Pacífico, tanto da atualidade quanto do final do século XIX -

Revista Eletrônica da ANPHLAC, ISSN 1679-1061, n.15, p. 307-312, jul./dez. 2013. 
não é abordado de maneira direta pela autora. Ela faz algumas referências ao evento, mas nada demonstra a relevância do embate ocorrido entre as marinhas peruanas e chilenas, no princípio da guerra, e que foi responsável pela construção de um imaginário nacionalista, fundamental para o arregimento do exército expedicionário chileno. A autora chega a apontar um de seus desdobramentos, ao descrever a cerimônia de chegada do navio peruano El Huáscar, capturado pela marinha chilena, como forma de demonstração de força, mas não aborda a importância desse ato para o contexto bélico.

Outro ponto importante que permanece inexplorado por McEvoy é a relação entre o jornal El Mercurio de Valparaiso, um respeitável veículo de comunicação da época, e o empresário chileno Agustín Edwards. Dono da Compañia de Salitre y Ferrocarril de Antofagasta, protagonista do estopim da guerra (pois foi a direção dessa companhia que recusou o aumento das taxas tributárias proposto pelo governo boliviano), Edwards comprou o jornal um ano antes do conflito e fez de suas páginas um porta-voz das ideias expansionistas do país. Envolvido diretamente no conflito, o empresário chileno era um importante ator histórico a ser apresentado aos leitores, uma vez que o argumento principal da autora é a composição política, social e cultural de seus participantes. Ela utiliza o jornal como fonte, ainda que poucas vezes, e não fez essa relação, que é de grande importância.

Faltou também ao texto a análise da relação previamente desenvolvida entre chilenos, bolivianos e peruanos nos territórios mineiros disputados. Como as indústrias de exploração mineral pertenciam aos capitalistas chilenos, a maior parte dos residentes nessas localidades era oriunda daquele país. As cidades da região foram construídas em função das mineradoras, e os trabalhadores utilizados nessas indústrias eram recrutados no Chile. A anexação de um território em que a população local, no caso os trabalhadores chilenos, se identifica com a nação "invasora" tem uma dinâmica diferenciada e deveria ter sido levada em consideração, no momento em que a autora analisou as relações sociais, políticas e culturais dos participantes do conflito.

A despeito destas observações, Guerreros Civilizadores é um livro importante para quem se interessa pela história e pela historiografia sobre a Guerra do Pacífico, sendo imprescindível para quem quer pesquisar e conhecer mais a respeito da formação das nações envolvidas no conflito. Com uma abordagem que vai além do campo

Revista Eletrônica da ANPHLAC, ISSN 1679-1061, n.15, p. 307-312, jul./dez. 2013. 
político, o livro mostra, por meio de variadas fontes, o processo de incorporação de parte dos territórios do Peru e da Bolívia pelo Estado chileno. Os desdobramentos da Guerra do Pacífico podem ser vistos, nos dias de hoje, nos sucessivos apelos das nações vencidas à Corte Internacional de Haya. A nova configuração geográfica definida após o conflito continua sendo discutida pelos países envolvidos e ratifica a necessidade de ampliar os estudos sobre o tema em questão.

Revista Eletrônica da ANPHLAC, ISSN 1679-1061, n.15, p. 307-312, jul./dez. 2013. http://revista.anphlac.org.br/ 